\title{
Odontologia Legal e Forense na formação de estudantes de Odontologia: relato de experiência de projeto de ensino multidisciplinar
}

\author{
Rafaela Martins Felippe*; Paulo Roberto dos Reis da Rosa**; Carolina Schuster Ouriques***; \\ Mohammed Irfan****; Luciana Domingues Conceição****; Rafael Guerra Lund***** \\ * Estudante, Curso de Química Forense, Centro de Ciências \\ Químicas, Farmacêuticas e de Alimentos, Universidade \\ Federal de Pelotas \\ ** Estudante, Curso de Graduação em Ciência e Engenharia de \\ Materiais, Centro de Desenvolvimento Tecnológico, \\ Universidade Federal de Pelotas \\ *** Estudante, Faculdade de Odontologia, Universidade \\ Federal de Pelotas \\ **** Pós-Doutorando(a), Programa de Pós-Graduação em \\ Odontologia, Universidade Federal de Pelotas \\ ***** Professor, Departamento de Odontologia Restauradora, \\ Faculdade de Odontologia, Universidade Federal de \\ Pelotas
}

Recebido em 30/09/2019. Aprovado em 12/07/2020.

\begin{abstract}
RESUMO
Este artigo objetivou relatar a experiência de um projeto de ensino multidisciplinar de Odontologia Legal e Ciências Forenses, voltado aos estudantes universitários e à comunidade acadêmica em geral. O projeto, por meio de encontros quinzenais com minicursos, grupo de estudos de livros didáticos e artigos científicos, além de outras atividades, estimulou a discussão e o aprendizado dessas áreas temáticas que estão cada vez mais em foco. Com fins didáticos, foi montada uma sequência de assuntos de Odontologia Legal e Ciências Forenses, possibilitando aos estudantes a experiência da perícia criminal, a partir do contato com ensaios simples, cujos conceitos jurídicos e forenses envolvidos estão presentes no currículo vivenciado em diferentes cursos universitários. As palestras realizadas quinzenalmente possibilitaram ao público (graduandos e professores) a troca de conhecimento sobre as diferentes áreas que abrangiam o projeto. Os assuntos abordados nas palestras foram especialmente importantes nas áreas que englobam as Ciências Forenses, principalmente a Química Forense e a Odontologia. O projeto de ensino intitulado: "Odontologia Legal e Forense" pode exercer um papel fundamental na formação acadêmica, tanto de futuros cirurgiões-dentistas quanto de futuros peritos, possibilitando vasto conhecimento em diferentes áreas das Ciências Forenses.
\end{abstract}

Descritores: Odontologia Legal. Ciências Forenses. Projeto de Ensino. Comunicação Interdisciplinar. 


\section{INTRODUÇÃO}

Odontologia Forense é o ramo da Medicina Forense que, no interesse da justiça, é responsável pelo exame de evidências dentárias, com a avaliação e apresentação adequada de achados dentários ${ }^{1}$.

Os especialistas em Odontologia Legal, por meio de suas habilidades específicas e seus conhecimentos científicos, estão aptos a obter informações precisas, gerando conclusões confiáveis para a identificação humana, principalmente quando se tem documentação antemortem, como o prontuário odontológico ${ }^{2}$. $\mathrm{O}$ odontolegista, cirurgião-dentista especialista em perícias, deve se dedicar ao sistema jurídico e aderir à ética ${ }^{3}$. Ele aplica seus conhecimentos para elucidação da verdade no ambiente administrativo, judiciário e legislativo ${ }^{4}$. O perito odontológico tem um papel de suma importância devido ao fato de que, caso haja falha no preenchimento dos laudos odontológicos, isso resultará em perícias imprecisas, retardamento dos processos e eventual acréscimo de custos. Logo, deve ser ressaltada a relevância do perito odontológico, principalmente no processo de preenchimento e guarda dos prontuários ${ }^{5}$.

Sendo assim, a atuação do odontolegista é de extrema importância em desastres em massa, principalmente quando há corpos carbonizados e/ou mutilados, pois nestes casos o exame do DNA possui limitações e, como alterativa, realiza-se o exame das arcadas dentárias e da cavidade bucal, visto que os dentes são estruturas altamente resistentes, inclusive a temperaturas elevadas e fornecem informações individuais que podem auxiliar nas investigações ${ }^{6}$.

A Odontologia Legal é uma especialidade que tem, dentre as suas áreas de atuação, a identificação humana. Ela é essencial nos institutos médicos legais, pois completa a equipe multiprofissional das Ciências Forenses.

Em casos de corpos carbonizados, mutilados, esqueletizados e putrefeitos, em que a identificação papiloscópica não é possível, as informações odontológicas são capazes de fornecer dados que auxiliam na identificação ${ }^{7}$.

Além disso, os materiais restauradores possuem resistência a condições extremas, como a cremação, sendo importante o odontolegista na unicidade do trabalho restaurador da identificação ${ }^{8}$. Além destes aspectos abordados, os peritos também devem levar em consideração os dados postmortem, que podem, por exemplo, demonstrar uma perda dental durante o processo de esqueletização ou danos causados pela recuperação, transporte e armazenamento inadequado do crânio ${ }^{3}$.

Por isso, é necessário estabelecer um consenso em alguns procedimentos forenses realizados durante o postmortem, como coleta, preservação e análise de evidências, e na técnica de identificação mais adequada com base na situação do desastre ${ }^{9}$.

Neste sentido, a Odontologia Legal, componente curricular da maioria dos cursos de graduação em Odontologia no Brasil, é vista corriqueiramente como sendo burocrática e morosa, por tratar de assuntos supostamente teóricos e distantes da prática odontológica tradicional. No entanto, a gama de assuntos que tem a oferecer é muito ampla, trazendo conteúdo das interfaces com outras áreas forenses ${ }^{10}$.

A Odontologia Legal tem por base fornecer auxílio no âmbito pericial, seja em acidentes automobilísticos, imprudência e negligência por profissionais, tratamentos não correspondidos, entre outros. A literatura mostra que o profissional da Odontologia interfere de forma legal e benéfica, melhorando expressivamente os resultados periciais ${ }^{11}$. O cirurgião-dentista, pelos seus primordiais conhecimentos técnicocientíficos especializados, é o profissional de mais adequada competência para realizar exames periciais na região da cabeça e pescoço ou 
vestígios correlatos ${ }^{12}$.

Odontologia Forense é a ciência forense que se preocupa com as evidências dentárias. É uma ciência relativamente nova que utiliza o conhecimento do cirurgião-dentista para servir o sistema judicial. A identificação humana depende muito da qualidade dos registros dentários ${ }^{1,13}$.

O objetivo da Odontologia Forense é a pesquisa de fenômenos psíquicos, físicos, químicos e biológicos que possam afetar ou já afetaram pessoas, vivas, mortas ou seus ossos e até fragmentos ou traços, resultando em lesões parciais ou totais, reversíveis ou irreversíveis ${ }^{14}$.

$\mathrm{O}$ presente artigo relata a experiência de um projeto de ensino intitulado "Odontologia Legal e Forense", que objetivou inserir o estudante de graduação no universo das ciências forenses e suas atribuições nessa esfera, propiciando o contato com diferentes áreas do conhecimento e o desenvolvimento do pensamento crítico acerca de suas futuras responsabilidades profissionais.

\section{RELATO DE EXPERIÊNCIA}

O projeto de ensino se desenvolveu entre maio e novembro de 2018 e, posteriormente, os minicursos retornaram de março a julho de 2019. As palestras foram realizadas quinzenalmente, em 10 encontros, constituídos por 9 palestras e 1 hands-on apresentados de forma expositiva, com o auxílio de multimídia e duração de duas horas cada, perfazendo 20 horas presenciais. O público era composto em média por 20 a 25 graduandos e docentes dos cursos de Odontologia, Química Forense, Química (Bacharelado e Licenciatura), Ciência e Engenharia de Materiais, Ciências Biológicas, Biologia, Biotecnologia, Farmácia, Artes visuais, Arqueologia e Antropologia. O projeto de ensino possibilitou ao graduando o contato com diferentes áreas do conhecimento jurídico e das Ciências Forenses, fazendo-o assim adquirir experiência na coleta e interpretação de dados, tanto de natureza criminal quanto cível, das diversas áreas periciais. Além disso, o projeto auxiliou o estudante a desenvolver pensamento crítico, acerca de sua responsabilidade profissional e a relação com o paciente. Isso era constatado nos diálogos realizados após as palestras, quando era aberto um espaço para discussão e questionamentos. Dessa forma, conseguiu-se verificar a importância do projeto na construção da reflexão do aluno no decorrer das palestras, uma vez que conforme iam ocorrendo os encontros, os alunos eram cada vez mais instigados a pensar na sua responsabilidade como profissional, e realizavam indagações acerca dos temas. Ademais, o projeto ampliou a rede de contatos do estudante na área de Ciências Forenses, pois os aproximou de profissionais e estudantes de outras áreas, como o Direito, a Biologia, a Química Forense e cursos afins.

No decorrer do projeto, foram abordados conceitos iniciais, definições e informações relativas à Odontologia Legal, assim como sua relação com outras áreas do conhecimento. Os assuntos dissertados nos encontros foram ministrados por professores colaboradores, uma especialista em Odontologia Legal e pelo professor coordenador do projeto de ensino, e incluíam: definição de local do crime, análise da cena do crime, introdução às Ciências Forenses, perfil do profissional, identificação de vítimas de desastres, Tanatologia Forense, perícia civil em odontologia, identificação pela arcada dentária, Asfixiologia Forense, Traumatologia Forense, apresentação de técnicas de identificação de restaurações dentárias para fins forenses: técnica com corantes e técnica de fluorescência (minicursos teórico-práticos), Química Forense, peritagem de arte e anatomia, Antropologia Forense, Balística Forense, reveladores de impressões digitais, investigação e autenticação 
de bens culturais e Entomologia Forense no Rio Grande do Sul. Estes assuntos eram abordados de forma expositiva, com diversas imagens de casos reais, sendo a identidade da vítima preservada.

Em seguida, ao fim de cada palestra, havia uma sessão de 15 a 30 minutos de debates entre o palestrante e o público acadêmico, a respeito dos assuntos abordados, sendo esse tempo muito proveitoso para a troca de conhecimento e esclarecimento de dúvidas sobre o tema. Neste momento, o estudante também demonstrava o seu interesse pela área e anseio em aprender mais sobre os assuntos abordados. Os docentes também trocavam conhecimentos com o ministrante, possibilitando assim uma interação maior e mais proveitosa dos conteúdos abordados durante a palestra, tornando-a de maior valia na formação acadêmica dos estudantes.

Cada conteúdo selecionado foi disponibilidade na sequência de minicursos, para efetivar o aprendizado. $\mathrm{O}$ minicurso eleito para ter uma parte prática foi "Apresentação de técnicas de identificação de restaurações dentárias para fins forenses: técnica com corantes e técnica de fluorescência", sendo este ministrado por uma pósdoutoranda, no formato de dois hands-ons, para melhor assimilação do conteúdo pelos acadêmicos, apresentando-se duas diferentes técnicas para identificação de materiais restauradores odontológicos com finalidade pericial. Durante as discussões sobre a identificação de restaurações odontológicas na área forense, foram demonstradas as técnicas com corante azul de metileno e de fluorescência, cujos objetivos eram realizar o reconhecimento e detecção de restaurações estéticas, confeccionadas com resinas composta, através de um corante ou luz ultravioleta.

O curso teórico-prático teve duração de duas horas. Na parte teórica, através de recursos de multimídia, os estudantes compreenderam o princípio das técnicas e receberam informações referentes aos materiais a serem utilizados, reagentes (corantes) e metodologia das análises. $\mathrm{Na}$ prática realizada, foi abordado o tema identificação de restaurações de resina composta de diferentes marcas, utilizando-se a técnica com o corante azul de metileno e a técnica de fluorescência. $\mathrm{O}$ método com corantes tinha o objetivo de detectar o material restaurador estético, melhorando a sua visualização durante o exame odontolegal. Os protocolos e corantes propostos melhoravam a inspeção visual dos dentes para detecção da presença de restaurações estéticas de resina composta. Portanto, eles poderiam ser propostos como métodos adjuntos não-invasivos no processo de identificação da vítima. Corantes mais escuros, como o azul de metileno promovem uma melhoria adicional na detecção visual ${ }^{8}$. Com o mesmo objetivo, a técnica de fluorescência ainda permitia a classificação das resinas compostas em uma escala de fluorescência, possibilitando saber a marca dos materiais que haviam sido utilizados durante esta atividade prática com os estudantes.

Foram levados para o procedimento experimental diferentes dentes restaurados com distintas marcas de resina composta. Juntamente com as amostras, constavam alguns equipamentos que seriam utilizados durante o processo. Para a metodologia com corantes, foram utilizados dentes restaurados, caneta aplicadora com corante azul de metileno, aplicadores com ácido hidrofluorídrico $10 \%$ e ácido fosfórico 37\%, gaze, luvas de procedimento, protetor de bancada, álcool etílico $70 \%$. Para a metodologia de fluorescência, foi utilizada uma câmera fotográfica Reflex (Nikon D7000 DLS-R, Nikon Corporation, Tokyo, Japan), envelopes identificados com as amostras de resina composta, pinça metálica, luva de procedimento, câmara escura (figura 1), lanterna de luz UV (UltraFire WF-501B, Arizona Tactical Gear, Phoenix, AZ) e notebook para análise das amostras 
no Photoshop (Photoshop CS6- Adobe Systems Inc., San Jose, CA).

Após as demonstrações, houve uma breve discussão com relação ao material a ser periciado e a análise pertinente ao início da investigação fictícia. Finalizando essa parte prática, na qual o estudante teve contato com duas técnicas odontológicas, e juntamente com a aplicação dos conceitos vistos anteriormente nas palestras quinzenais, os graduandos viveram a experiência de como ser odontolegista por um dia.

O minicurso teórico-prático ministrado pela pós-doutoranda do projeto demonstrou que a maioria dos estudantes advindos dos mais diferentes cursos universitários que participavam do projeto, incluindo alguns menos interessados e animados com as palestras quinzenais, mostraramse instigados no estudo das Ciências Forenses, o que proporcionou também maior facilidade na discussão dos assuntos. Além da abordagem contextualizada que a exibição de alguns minicursos possibilitou, os estudantes despertaram interesse em saber como era possível trazer a química e a odontologia para o ambiente de perícia.

Esses métodos de identificação humana são de extrema importância para o avanço das Ciências Forenses, pois além de facilitar o trabalho dos peritos criminais, principalmente em casos de desastres em massa, também podem ser usados em campo, pois são rápidos, simples e de baixo custo ${ }^{8}$.

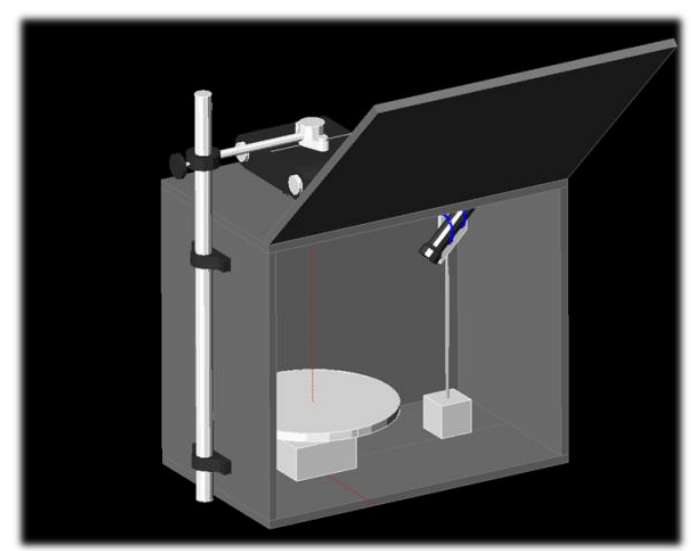

Figura 1. Esquema 3D (caixa em MDF, medidas: $45 \mathrm{~cm}$ altura $\mathrm{x} 45 \mathrm{~cm}$ profundidade $\mathrm{x} 45 \mathrm{~cm}$ largura)

A equipe de professores e pós-graduandos que compunham o projeto de ensino também orientou artigos e pesquisas científicas sobre Odontologia Legal e Forense, visando o progresso e o aperfeiçoamento da área no contexto regional, nacional e internacional, buscando assim cada vez mais expandir os conhecimentos adquiridos pelos alunos no âmbito das Ciências Forenses. Ao longo do projeto, foram desenvolvidas algumas publicações científicas pelo grupo, todas voltadas para o campo da Odontologia Legal, sendo algumas delas citadas neste trabalho ${ }^{8,16}$.

O projeto teve início no ano de 2017, e possuía uma página na rede social Facebook, uma conta no Instagram e um grupo no aplicativo de mensagens WhatsApp, para que, desta maneira, um maior número de pessoas pudesse ter contato com o projeto, sendo o maior número de seguidores da área de Odontologia, seguido pela área de Química Forense. As postagens eram vinculadas ao projeto de ensino, divulgação 
das informações das palestras, notícias, curiosidades e artigos relacionados à área forense, aspectos jurídicos e éticos que cercam a prática odontológica, além do compartilhamento de eventos de Ciências Forenses de outros grupos acadêmicos e projetos parceiros.

Como os odontologistas forenses estão desempenhando um papel importante no processo de identificação de vítimas de desastres em massa: DVI (Disaster Victim Identification), e em outros casos médico-legais, é urgente promover a especialidade de Odontologia Legal e Forense. Iniciativas de sensibilizar os graduandos para as áreas forenses e conferir aos dentistas a experiência em casos relacionados a perícias, incentivando-os a fazer parte de equipes de investigação e identificação humana, pode ajudar a estabelecer a Odontologia Forense como uma especialidade separada em Ciências Forenses ou Ciências Dentárias ${ }^{17}$.

No ano de 2019, até o mês de julho, foram alcançadas 687 curtidas e 703 seguidores na página do Facebook deste projeto de ensino e 457 seguidores no Instagram, sendo que algumas publicações chegaram ao alcance de mais de 980 pessoas. O grupo no WhatsApp contava com 27 participantes.

O Projeto de Ensino Odontologia Legal e Forense teve o intuito de promover integração entre as diversas áreas forenses, promoção de atividades específicas para o público acadêmico, produção de trabalhos e pesquisas, possibilitando aos integrantes do projeto maior conhecimento e informações acerca deste tema.

\section{CONSIDERAÇÕES FINAIS}

Depois de encerradas as atividades pertinentes ao projeto em questão, pode-se afirmar que um ensino diferenciado, seja ele por meio de aulas práticas ou predominantemente com a inserção de minicursos teóricos quinzenais em multimídia, mostrou-se muito eficaz e dinâmico, tanto para os graduandos quanto para os professores. Isso pôde ser evidenciado pelo número expressivo de alunos e professores que reportavam, através de discussões após os minicursos e aulas práticas, ou até mesmo pelas redes sociais, a sua avaliação positiva acerca das atividades desenvolvidas nesse projeto. Além disso, observava-se que não era comum haver um grande público com interesse e engajamento em atividades extracurriculares realizadas no período noturno naquela universidade, como havia ocorrido com a realização deste projeto de ensino em Odontologia Legal e Forense.

Além disso, o uso de recursos audiovisuais também foi uma importante ferramenta didática facilitadora do processo ensino-aprendizagem, juntamente com os conteúdos programáticos e materiais complementares, como artigos científicos e notícias atualizadas divulgadas nos canais de comunicação do projeto (redes sociais e WhatsApp), observando-se que este conjunto de recursos contribuiu muito no decorrer das atividades propostas.

Diante disso, conclui-se que o Projeto de Ensino Odontologia Legal e Forense pode exercer papel fundamental na formação acadêmica dos futuros cirurgiões-dentistas, e também de outros profissionais, possibilitando vasto conhecimento nas diferentes áreas das Ciências Forenses.

\section{AGRADECIMENTOS}

À Pró-Reitoria de Ensino da Universidade Federal de Pelotas e ao Conselho Nacional de Desenvolvimento Científico e Tecnológico (CNPq 465450/2014-8) pela concessão de bolsas de extensão universitária e pós-doutorado (respectivamente) para a realização deste projeto.

\section{ABSTRACT \\ Legal and Forensic Dentistry in the formation of dental students: an experience report of a}




\section{multidisciplinary learning project}

It is the purpose of this paper to report the experience of a multidisciplinary teaching project of Legal Dentistry and Forensic Sciences, aimed at university students and the academic community in general. The project, through biweekly meetings with short courses, a group of textbook studies and scientific articles as well as other activities, stimulated the discussion and learning of these thematic areas that are increasingly in focus. For didactic purposes, a sequence of subjects of Legal Dentistry and Forensic Sciences was set up, allowing students to experience criminal expertise, through contact with simple essays, whose legal and forensic concepts involved are present in the curriculum experienced in different university courses. The biweekly lectures enabled the public (undergraduates and teachers) to exchange knowledge about the different areas that comprise the project. The subjects covered in the lectures are especially important in the areas that encompass Forensic Sciences, especially Forensic Chemistry and Dentistry. The teaching project entitled "Legal and Forensic Dentistry" can play a fundamental role in the academic formation, both for future dental surgeons and future experts, enabling vast knowledge in different areas of Forensic Sciences.

Descriptors: Forensic Dentistry. Forensic Sciences. Teaching Project. Interdisciplinary Communication.

\section{REFERÊNCIAS}

1. Kapoor R, Singh R, Singh K, Kaur K. "Denture Marking". A novel concept in human identification. IOSR J Dent Med Sci. 2015;14(3):67-70.

2. Mânica S. Outros desafios além da identificação de vítimas para o dentista forense que atua em desastres em massaconsiderações em literatura. Rev Bras Odontol Leg RBOL. 2016;3(1):60-9.

3. Vinutha YJ, Krishnapriya V, Shilpa G, Vasanti D. Forensic dentistry: a pedodontist's perspective. J Med. 2015;
1(2):8-14.

4. Silva RF, Franco A, Oliveira RN, Júnior ED, Silva RHA. A história da odontologia legal no Brasil. Parte 1: origem enquanto técnica e ciência. Rev Bras Odontol Leg RBOL. 2017;4(2):87-103.

5. Oliveira CF, Souza PO, Rodrigues LG, Mundim MB, Franco A, et al. Importância de marcas de mordida na Odontologia legal. Revisão de literatura. Monografia (Trabalho de Conclusão de Curso) - Faculdade de Odontologia de Piracicaba - UNICAMP. Piracicaba, 2005.

6. Coutinho CGV, Ferreira CA, Queiroz LR, Gomes LO, Silva UA. O papel do odontolegista nas perícias criminais. Rev Fac Odontol UPF. 2013; 18(2):217-23.

7. Argollo SP, Argollo BP, Argollo PAN, Marques JAM. Utilização da rugoscopia palatina para identificação de corpo carbonizado - relato de caso pericial. Rev Bras Odontol Leg RBOL. 2017;4(1):107-13.

8. Conceição LD, Pereira CMP, Forgie AH, Leite FRM. Staining protocols to improve the detection of composite restorations in human identification. Forensic Sci Int. 2019;297:198-203.

9. Puri PM, Khajuria H. Disaster Victim Identification (DVI) through dental evidence: overview and challenges in Indian scenario. Int J Res Sci Innov. 2015;2(2):547.

10. Brites NA, Pithan AS, Nunes MF, Brites IF. Odontologia Legal no ensino superior do Estado do Rio Grande do Sul. Rev ABENO. 2016;16(3):36-45.

11. Silva CHF, Junior ACHJ, Martins LFB. The importance of forensic odontologists and dental records to forensic and legal resolutions. Rev Expressão Católica Saúde. 2019;4(1):81-90.

12. Silva VR, Terada ASSD, Silva RHA. A 
importância do conhecimento especializado do cirurgião-dentista nas equipes de perícia oficial do Brasil. Rev Bras Odontol Leg RBOL. 2015;2(1):68-90.

13. Mishra SK, Mahajan H, Sakorikar R, Jain A. Role of prosthodontist in forensic odontology. A literature review. J Forensic Dent Sci. 2014;6:154-64.

14. Conceição LD, Silveira IA, Lund RG. Forensic dentistry: an overview of the human identifications techniques of this dental specialty. J Forensic Res. 2015;6:15.14 .
15. Conceição LD, Prietto NR, Silva RHA, Lund RG. Forensic dentistry in a southern Brazilian city. Rev Bras Crim. 2015;4:3340.

16. Conceição LD, Ouriques CS, Busnello AF, Lund RG. Importance of dental records and panoramic radiograph in human identification: a case report. Rev Bras Odontol Leg RBOL. 2018;5:68-75.

17. Krishan K, Kanchan T, Garg AK, Dental evidence in forensic identification - an overview, methodology and present status. Open Dent J. 2015;9:250-6.

\section{Correspondência para:}

Rafael Guerra Lund

e-mail: rafael.lund@gmail.com

Universidade Federal de Pelotas

Faculdade de Odontologia

Rua Gonçalves Chaves 457 Sala 503

96015-560 Pelotas/RS 